1 Universidade Estadual de Londrina (UEL), Departamento de Saúde Coletiva - Londrina (PR) Brasil.

brigidagimenez@gmail.com

2 Universidade Estadual de Londrina (UEL), Departamento de Saúde Coletiva - Londrina (PR) Brasil.

carolinamdomingos@gmail. com

3 Universidade Estadual de Londrina (UEL), Residência Multiprofissional em Saúde da Família - Londrina (PR) Brasil.

fernanda_leiti@hotmail.com

\section{Integralidade do cuidado no Programa de Controle do Câncer de Colo Uterino: visão das usuárias com alteração na citologia oncótica}

Integrality of health care in Control Program of Cervical Cancer: the view of users with occurrence of citopathological alteration

Brígida Gimenez Carvalho', Carolina Milena Domingos², Fernanda de Souza Leite ${ }^{3}$

RESUMO Objetivou-se avaliar a integralidade no cuidado de mulheres atendidas pelo Programa de Controle do Câncer de Colo Uterino. Estudo avaliativo, qualitativo, que analisou o acompanhamento e o tratamento de mulheres com alteração na citologia oncótica nos serviços que compõem a rede de atenção, segundo a percepção das mulheres entrevistadas no segundo semestre de 2013. Realizada a análise temática de conteúdo, verificou-se que o acesso ao exame não garantiu a continuidade do cuidado, devido à falta de acolhimento/vínculo e à dificuldade de acesso ao tratamento. Constata-se a necessidade de outras medidas de avaliação do programa que mensurem a integralidade do cuidado, para além da cobertura de exames.

PALAVRAS-CHAVE Integralidade em saúde; Acesso aos serviços de saúde; Acolhimento; Atenção Primária à Saúde.

ABSTRACT It was aimed to evaluate the integrality in health care of women treated by the Control Program of Cervical Cancer. Evaluative, qualitative study that examined the monitoring and the treatment of women with citopathological alteration in services that compose the network of care, according to the perception of women interviewed in the second half of 2013. Once performed the thematic content analysis, it was found that access to the examination did not ensure the continuity of care, due to the lack of receptiveness/link and to the difficulty in access to treatment. It was found the need of other assessment measures of the program, that measure the integrality in health care,beyond the coverage tests.

KEYWORDS Integrality in health; Health services accessibility; User embracement; Primary Health Care. 


\section{Introdução}

O câncer do colo do útero é um problema de alta magnitude e transcendência entre as mulheres. Anualmente, são diagnosticados 528 mil novos casos desse tipo de câncer, e estima-se que tenha sido o responsável pela morte de 266 mil mulheres no mundo no ano de 2012 (WHO, 2012). No Brasil, é o segundo tumor mais frequente entre a população feminina e a quarta causa de morte de mulheres por câncer (INCA, 2011).

Devido à magnitude do problema e com o intuito de incorporar a realização da detecção precoce da neoplasia, ações de prevenção do câncer têm sido desenvolvidas no Brasil desde 1984. Em 1998, foi criado o Programa Nacional de Combate ao Câncer de Colo do Útero (PNCCU), desenvolvido pelo Ministério da Saúde (MS), em parceria com o Instituto Nacional do Câncer (Inca). Em 1999, surgiu o Sistema de Informação do Câncer do Colo do Útero (Siscolo), para monitoramento e gerenciamento das ações (INCA, 2011).

No ano de 2005, foi instituída a Política Nacional de Atenção Oncológica, e, a partir de 2006, as ações de prevenção, detecção precoce e tratamento oportuno do câncer de mama e do colo de útero devem constar nos planos de saúde estaduais e municipais, como indicador universal para pactuação entre os gestores do Sistema Único de Saúde (SUS) (BRASIL, 2013).

Para que as metas e os indicadores pactuados sejam cumpridos, a Unidade Básica de Saúde (UBS) tem relevante papel enquanto coordenadora da rede de atenção, pois cabe a ela articular-se aos demais serviços que compõem a rede de atenção ao câncer, além de desenvolver ações relacionadas à coleta do exame papanicolau. Essa articulação deve ser realizada com o objetivo de ordenar o cuidado na referida rede, integrando ações de promoção e prevenção da saúde ao tratamento e à reabilitação, visando à garantia da integralidade da atenção às mulheres.

A discussão sobre integralidade, no Brasil, na área da gestão, apresenta dois eixos distintos, mas interligados. O primeiro refere-se à utilização das tecnologias de saúde disponíveis para todos os usuários do SUS, com base nas necessidades e com a prudência necessária a um bom resultado. $\mathrm{O}$ outro eixo trata de como implantar esse princípio estruturante. A aposta atual passa pela constituição de redes de atenção articuladas e ordenadas pela Atenção Básica, possibilitando a qualificação e a resolubilidade para a consequente integralidade da atenção (MAGALHÃES JÚNIOR, 2008).

Como ordenadora do cuidado na rede de atenção, é fundamental que os trabalhadores integrantes da equipe da UBS conheçam a população usuária de seu território e identifiquem grupos prioritários e/ou de risco e para os quais já existam ações e/ou programas estruturados. Essa estruturação, denominada ação programática em saúde, tem como proposta organizar o trabalho de saúde fundamentada no ideal da integração sanitária e inspirada em tecnologias de base epidemiológica, ou seja, possui uma racionalidade de intervenção que articula ações terapêuticas individuais e ações de saúde coletiva (SALA; NEMES; COHEN, 1996).

Tais ações são fundamentais quando se pensa na organização das demandas atendidas nas UBS pelo PNCCU, no entanto, necessitam de constantes avaliações que subsidiarão o planejamento e a readequação das atividades desenvolvidas. Para isso, devem-se avaliar as intervenções realizadas por meio de dispositivos que permitam fornecer informações cientificamente válidas e socialmente legítimas sobre aquela intervenção (FIGUEIRÓ; FRIAS; NAVARRO, 2010).

A maioria das avaliações de programas e serviços desenvolvidas no Brasil tem caráter normativo, com foco no alcance de metas de cobertura quanto ao número de consultas/ procedimentos realizados, sendo rara a utilização de indicadores de qualidade. Esses são facultativos e variam de acordo com as características dos serviços, das equipes e do processo de trabalho (SILVA JUNIOR; MASCARENHAS, 2004).

No caso do PNCCU, seria fundamental uma avaliação qualitativa, tendo em vista que a utilização de métodos estritamente 
normativos impossibilita avaliar se o tratamento em tempo oportuno foi atingido, já que, a depender de como as mulheres vivenciam e enfrentam esse problema na rede de serviços, determinará a realização ou não do acompanhamento e do tratamento necessários.

Desta forma, o estudo teve como objetivo avaliar a integralidade do cuidado prestado às mulheres atendidas pelo Programa, por meio da análise de como se deu o acesso ao resultado do exame, ao tratamento e como foi o acompanhamento das pacientes nos serviços que compõem a rede de atenção, segundo a percepção das próprias mulheres.

A rede de atenção e de controle do câncer uterino no município em que a pesquisa foi desenvolvida é constituída por UBS, laboratórios diagnósticos, hospitais gerais, hospital de referência para o tratamento do câncer e pelo consórcio intermunicipal de saúde, que disponibilizam serviços de apoio diagnóstico e terapêutico nessa área.

\section{Referencial teórico}

Neste estudo, a avaliação foi realizada na perspectiva da integralidade do cuidado prestado às mulheres no PNCCU. A integralidade é um termo polissêmico, que pode ser usado no sentido de um olhar para o ser humano como um todo - a integralidade vertical. Também pode ser utilizado no sentido do acompanhamento ao usuário em todos os níveis de atenção à saúde, no que se refere ao acesso à promoção, à prevenção, ao tratamento e à recuperação da saúde - a integralidade horizontal (CARVALHO, 2006).

Segundo Mattos (2001), a integralidade, desde a criação do SUS, segue sendo um bom indicador da direção a ser seguida pelo sistema e suas práticas. Esse mesmo autor aponta três conjuntos de sentidos do princípio da integralidade:

[...] o primeiro conjunto se refere a atributos das práticas dos profissionais de saúde, sendo valores ligados ao que se pode considerar uma boa prática; o segundo conjunto refere-se a atributos das organizações dos serviços; o terceiro aplica-se às respostas governamentais aos problemas de saúde. [...] Quer tomemos a integralidade como princípio orientador das práticas, quer como princípio orientador da organização do trabalho, quer da organização das políticas, integralidade implica uma recusa ao reducionismo, uma recusa à objetivação dos sujeitos e talvez uma afirmação da abertura para o diálogo. (MATTOS, 2001, P. 61).

Para Silva Junior e Mascarenhas (2004), a integralidade engloba o acolhimento, o vínculo e a qualidade da atenção. Para esses autores, o acolhimento envolve o acesso, seja geográfico ou organizacional, e a postura, tanto na escuta como na atitude profissional-usuário. $\mathrm{O}$ vínculo refere-se ao afeto, à continuidade do cuidado, pela aceitação e pelo relacionamento de confiança, expectativas, percepções e singularidades do usuário, além da adesão ao tratamento. É a relação terapêutica que reflete na eficácia do tratamento. Já a qualidade da atenção baseia-se na conduta profissional e na interação com o usuário. A relação profissional-usuário engloba satisfação, expectativas e adaptação. Buscam-se, como resultado, além da cura do biológico, também melhores atitudes e comportamentos (SILVA JUNIOR; MASCARENHAS, 2004).

\section{Método}

Trata-se de um estudo avaliativo, de natureza qualitativa, em que se realizou um monitoramento sistemático das mulheres atendidas pelo PNCCU em uma UBS no ano de 2012, cujos resultados dos exames de citologia oncótica estavam alterados.

Essa UBS se localiza em um município da região Sul do País e sua área de abrangência abarca uma população estimada de 9.568 
habitantes (BBGE, 2010), sendo que 50,8\% são mulheres. Estima-se que, na faixa etária de 25 a 64 anos, público alvo do PNCCU, residem no território dessa UBS 2.600 mulheres. No ano de 2012, a meta pactuada da unidade em estudo para cobertura de exames de Citologia Oncótica (CO) foi de 650 exames coletados. Naquele ano, essa meta foi superada, tendo sido atingida uma cobertura de CO de $112 \%$.

Com relação à população de estudo, os critérios de inclusão foram: ter coletado CO no ano de 2012, ter alguma alteração no resultado do exame e residir na área de abrangência da UBS. Os critérios para exclusão foram: não ter alteração no resultado de CO coletado na UBS no ano de 2012, ter se mudado da área de abrangência, ou não pertencer a ela, e, mesmo que residindo na área, não ter sido encontrada em sua residência após três visitas, realizadas em dias e horários alternados. Desta forma, a população inicial de estudo foi composta por 26 mulheres que tiveram seu exame de $\mathrm{CO}$ alterado.

Foram consideradas alterações no exame de CO as seguintes atipias celulares: células atípicas de significado indeterminado em células escamosas; lesão intraepitelial de baixo grau em células escamosas; células atípicas de significado indeterminado em células glandulares; células atípicas de significado indeterminado de origem indefinida; lesão intraepitelial de alto grau, não podendo excluir microinvasão; carcinoma epimoide invasor em células escamosas; adenocarcinoma in situ; adenocarcinoma invasor, cervical, endometrial, sem outras especificações; e outras neoplasias malignas em células glandulares (LONDRINA, 2006).

Os dados da população de estudo foram obtidos por meio dos relatórios de acompanhamento do PNCCU da UBS, do ano de 2012. A partir da identificação das mulheres, foram realizadas visitas domiciliares para realização de entrevistas com um roteiro semiestruturado, no período de julho a agosto de 2013. O roteiro contemplou, além de questões sobre a caracterização (nome, idade, escolaridade), e que serviram para descrever o perfil das mulheres pesquisadas, outras questões que permitiram conhecer a percepção de como receberam o resultado do exame alterado e como se deram o acompanhamento e/ou o tratamento na UBS e na rede se serviços.

As mulheres foram esclarecidas sobre o objetivo da pesquisa e lhes foram garantidos o anonimato e o sigilo no tratamento dos dados, bem como a possibilidade de desistirem de sua participação em qualquer etapa da pesquisa. Após receberem todas as informações, as que concordaram em participar preencheram o termo de consentimento livre e esclarecido. Todas as entrevistas foram gravadas e transcritas na íntegra. Após transcrição, os dados foram trabalhados e editados para a correção gramatical, excluídos os vícios de linguagem, as pausas e interferências, para guiar o leitor à compreensão do sentido da entrevista. Para não identificar os depoimentos, esses foram codificados com letra e número (E1, E2... En), na ordem em que foram realizadas as entrevistas.

Para análise do material empírico, foi utilizada a técnica de análise temática de conteúdo, que "consiste em descobrir os núcleos de sentido que compõe a comunicação e cuja presença, ou freqüência de aparição, pode significar alguma coisa para o objetivo analítico escolhido" (BARDIN, 2009, P. 131).

A análise de temática de conteúdo prevê a organização e a realização das atividades em três etapas: a pré-análise; a exploração do material e o tratamento dos resultados, ou seja, a inferência e a interpretação. A pré-análise consistiu numa fase de organização do material, e foi realizada a leitura flutuante, de forma a possibilitar a impregnação do seu conteúdo. A exploração do material consistiu em operações de codificação/categorização, processo pelo qual os dados brutos foram transformados e agregados em unidades. O tratamento dos resultados consistiu na interpretação da categorização realizada, com base no referencial teórico de integralidade proposto por Junior e Mascarenhas (2004).

Os aspectos éticos foram respeitados. 
A pesquisa foi submetida e aprovada pelo Comitê de Ética da Universidade Estadual de Londrina, sob o parecer $\mathrm{n}^{\circ} 053 / 2013$, CAAE $n^{\circ} 15588213.0 .0000 .5231$.

\section{Resultados e discussão}

\section{Caracterização da população de estudo}

Das 26 mulheres que tiveram o exame de CO alterado no ano de 2012, cinco residiam fora da área de abrangência da UBS; três se mudaram do território assistido pela unidade; duas possuíam endereço informado inexistente; uma não teve o endereço informado; e uma estava viajando durante o período em que foram realizadas as três visitas domiciliárias. Assim, foram entrevistadas 14 mulheres identificadas na área de abrangência da UBS. Das mulheres participantes do estudo, três não realizaram o tratamento indicado; quatro apenas começaram e abandonaram o tratamento; quatro ainda estavam em acompanhamento; e apenas três já haviam concluído o

Figura 1. Fluxograma de identificação da população de estudo e realização do tratamento indicado

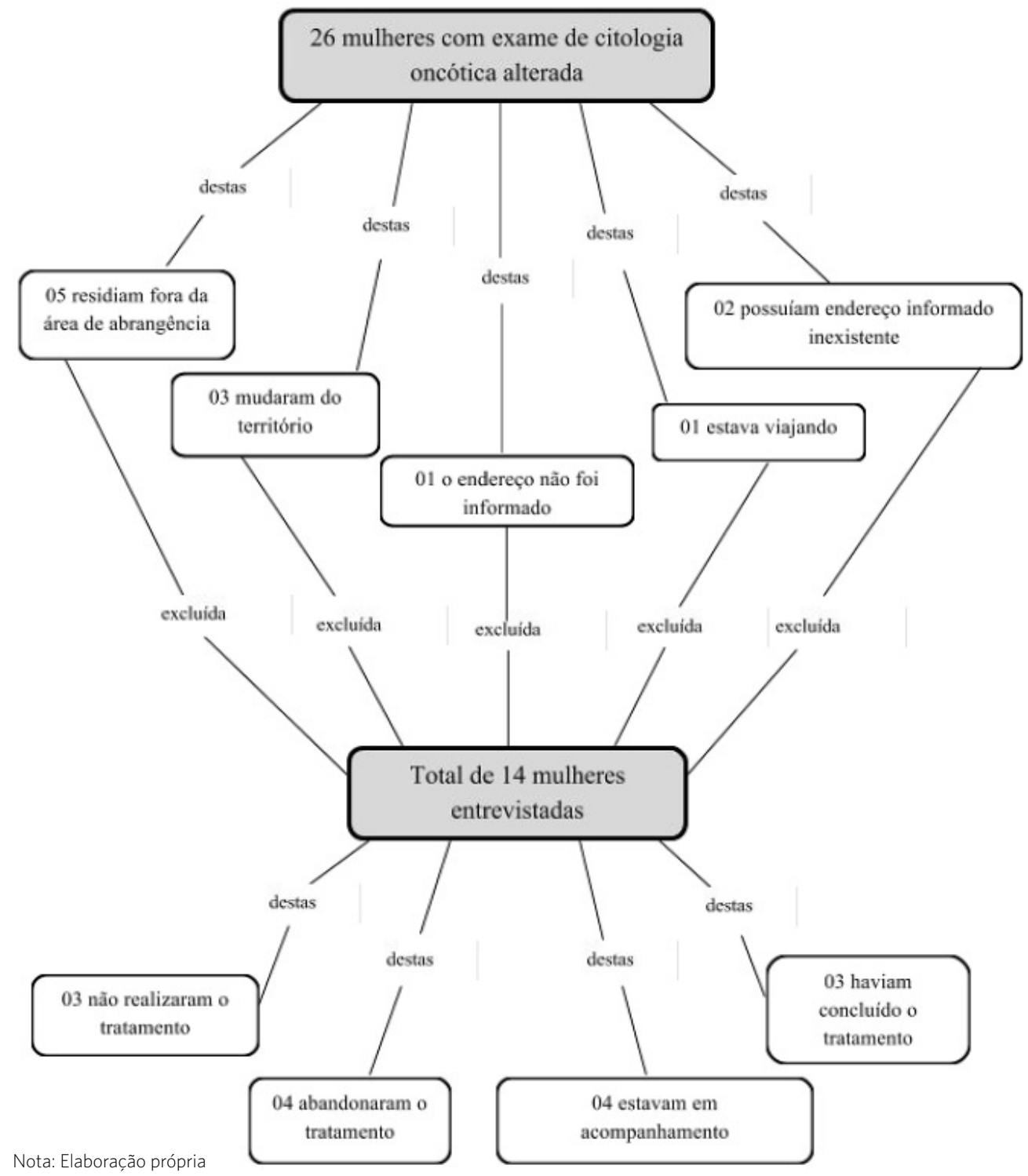


tratamento à época da entrevista (figura 1).

Com relação à idade das entrevistadas, a maioria $(78,6 \%)$ estava na faixa etária de 25 a 64 anos, priorizada pelo programa de controle do câncer de colo de útero para a realização do exame. Entretanto, um percentual significativo das participantes $(21,4 \%)$ com exame alterado possuía idade entre 15 a 24 anos.

Quanto à escolaridade, a maioria possuía ensino médio $(35,7 \%)$ e fundamental $(14,2 \%)$ completo. A minoria $(14,2 \%)$ das mulheres iniciou o ensino superior, no entanto, nenhuma o havia concluído à época da entrevista. Quanto à ocupação, a maioria das participantes do estudo trabalhava fora de casa $(71,4 \%)$.

Com relação ao tipo de alteração no resultado dos exames, quatro corresponderam a metaplasia escamosa imatura, duas possivelmente não neoplásicas, duas NIC I e seis NIC II/ III. Já na busca e na caracterização da população de estudo, a impossibilidade de identificação de 12 (46\%) das 26 mulheres que tiveram seu resultado de exame alterado e o abandono ou não realização do tratamento de sete (50\%) das 14 mulheres encontradas demonstram a fragilidade da UBS na identificação e na localização da população adscrita.

A execução das práticas de saúde sobre um território e a estratégia de territorialização, com adscrição da população e realização de busca ativa da mesma, contribuem para a garantia do acesso e a continuidade do cuidado (SANTOS; RIGOTTO, 2010). No entanto, para esses autores, a territorialização no contexto das ações da Atenção Básica (AB) à saúde vem sendo tratada de forma parcial. A ênfase nas características geográficas do local para fins administrativos tem limitado suas possibilidades de identificação de questões de saúde e das correspondentes iniciativas de intervenção concreta na realidade cotidiana da população, ou mesmo na importância da identificação do indivíduo (SANTOS; RIGOTTO, 2010).

Para além dessa dimensão, o território, na condição de cotidiano vivido no qual se dá a interação entre as pessoas e os serviços de saúde no nível local do SUS, caracteriza-se por uma população específica, com seus respectivos problemas de saúde. A compreensão do território, com toda a sua riqueza e complexidade, sinaliza uma etapa primordial para a caracterização descritiva e analítica das coletividades humanas e de seus problemas de saúde, abrindo espaços para o desenvolvimento de práticas de saúde voltadas para as pessoas (SANTOS, 2008).

De acordo com a portaria $n^{0} 2.488$, de 21 de outubro de 2011, que aprova a Política Nacional de Atenção Básica, faz parte do escopo de seus fundamentos e diretrizes, além de a equipe atuar em um território adscrito, desenvolver relações de vínculo e responsabilização para com a população desse território. Essas relações colaboram para o alcance da longitudinalidade do cuidado. Desta forma, a relação entre trabalhador e usuário é permeada pela confiança e pelo afeto que permitem a construção do vínculo e da responsabilização pelo cuidado de modo constante ao longo do tempo. Tal possibilidade colabora para que os efeitos das intervenções em saúde e de outros elementos na vida dos usuários sejam conhecidos e acompanhados pela equipe de saúde da UBS (BRASIL, 2011).

\section{Acesso e acolhimento na perspectiva da integralidade do cuidado}

As mulheres participantes do estudo referiram fragilidades e potencialidades quanto ao acesso e ao acolhimento do serviço de saúde como medidas complementares para a garantia da continuidade do cuidado e do consequente alcance da integralidade do serviço prestado.

De acordo com as falas das usuárias, a 
dificuldade da continuidade do cuidado já fica evidente no momento da coleta do preventivo, sendo ressaltado como "algo constrangedor" (E10); "chato e vergonhoso" (E07); "Horrível! Não vai! Na hora, parece que eu estou fazendo uma cesárea, muito horrível. Eu não gosto" (E11), o que pode resultar na recusa da mulher em realizar o tratamento. Oliveira et al. (2008) referem que as consequências do primeiro encontro entre profissional e usuário alteram de forma decisiva a passagem do usuário pela unidade e a resolução de seus problemas.

Apesar de expressarem esses sentimentos, a maioria das participantes do estudo reconhece o exame como necessário para $o$ diagnóstico de patologias e que sua realização deve ser constante:

Quando eu fiz a primeira vez, foi esquisito, mas é sempre bom prevenir, por causa de doenças, câncer. O médico me explicou tudo como funciona [...] é sempre bom fazer. Se ocorrer alguma alteração, tratar também. (E07).

As entrevistadas citaram, como uma fragilidade do serviço, a forma de comunicação das alterações demonstradas nos resultados dos exames, feita por telefone pelos profissionais da unidade, sendo referida como fato que gerou ansiedade e desconforto nas usuárias. Houve um caso em que o resultado do diagnóstico foi informado de forma incorreta, e a usuária, entendendo que o resultado estava normal, não retornou para o tratamento: "Deu tudo certo [...] não tinha nenhuma alteração" (E07).

Outra barreira apresentada "foi a demora que você leva para conseguir determinada consulta" (E04) com o ginecologista da UBS em tempo oportuno para o tratamento. Esse fato foi indutor da busca de serviço de saúde especializado privado, sem ter havido encaminhamento da UBS: "Não [fui encaminhada], fui direto pra lá porque eu desisti. Eu não quis passar com o ginecologista do posto porque não tinha muita vaga" (E01).

Os resultados levam a pensar sobre o problema do acesso ao tratamento necessário. Durante o processo de construção do SUS, foi propagado que a implementação da Estratégia Saúde da Família, de suas ações e serviços, ampliou o acesso aos usuários. Tal afirmação é válida quando se pensa na dimensão quantitativa do acesso: aumento do número de pessoas atendidas pelo sistema na Atenção Básica. No entanto, torna-se indispensável passar do enfoque estritamente quantitativo para o qualitativo, ou seja, considerar, além do primeiro atendimento, a continuidade do cuidado na rede de atenção e a qualidade do cuidado ao usuário (MERHY, 1998; CAMPOS, 1998; CAMPOS, 2003; MERHY ET AL.,2003).

Starfield (2004) discute acesso e acessibilidade, demonstrando que os significados desses termos se complementam, na medida em que acessibilidade possibilita que as pessoas cheguem aos serviços, e o acesso permite o uso oportuno dos serviços para alcançar os melhores resultados possíveis.

A demora da consulta com o ginecologista da unidade foi a justificativa dada pelo trabalhador de saúde para recomendar à usuária a procura de um serviço privado. Essa conduta contraria o conceito de acesso como a possibilidade da consecução do cuidado, de acordo com as necessidades de saúde. A inter-relação do acesso com a resolubilidade extrapola a dimensão geográfica, abrangendo aspectos como a oferta de serviços (SOUZA ET AL., 2008). Os encaminhamentos efetuados sem que tenham sido esgotados todos os recursos das ações e dos serviços da rede básica demonstram desresponsabilização com o cuidado ao usuário, levando ao aumento desnecessário da utilização dos serviços de média e alta complexidades. $\mathrm{O}$ atual modelo assistencial biologicista, médico centrado, gera um excesso de encaminhamentos para especialistas, alto consumo de exames e serviços pouco resolutivos (CAMPOS, 1992; MERHY, 1998), e não garante a integralidade da atenção ao usuário.

Além disso, vale lembrar o papel da $\mathrm{AB}$ 
nas redes de atenção em saúde. De acordo com a Política Nacional de Atenção Básica (BRASIL, 2011), para o funcionamento das redes de atenção à saúde, a $\mathrm{AB}$ tem que ser a base, tem que ser resolutiva. Sua participação no cuidado se faz sempre necessária, devendo, por meio de uma clínica ampliada, ser capaz de construir vínculos e intervenções clínica e sanitariamente efetivas.

Outros fatores que atuaram como empecilho para o tratamento foram as singularidades e especificidades das usuárias: a condição de estar gestante, em um dos casos, e a crise hipertensiva no momento da cirurgia, em outro, fizeram-nas abandonar o tratamento. Outra usuária referiu que o fato de ser a chefe da família e ter de cuidar das filhas também dificultou a continuidade do tratamento: "Foram as meninas mesmo, porque não tem como. Minha mãe tem que trabalhar, sabe? Quando ela estava de férias, ela ficava pra mim, mais [...] é relaxo meu mesmo" (E08).

No entanto, também houve potencialidades citadas pelas participantes do estudo. Uma usuária referiu estar satisfeita com o atendimento e o tratamento recebido: "Já me encaminharam, me chamaram pra ir ao Hospital do Câncer e já foi feita a cirurgia [...]” (E02), pois, havendo necessidade de encaminhamento, existe facilidade de agendamento e realização de exames. Esta atribui a percepção positiva sobre o cuidado que recebeu ao fato de ter sido 'bem informada': "A enfermeira me informou, me orientou $e$ me ajudou a marcar o mais rápido possível. Pelo problema de base, me chamaram mais rápido" (E02).

Para outra participante do estudo, houve escuta do usuário:

a médica era bem tranquila, ela conversou bem. Ela até falou, se não tivesse procurado logo, tinha virado um câncer de útero. Ainda falei pra ela que eu sempre faço o exame, porque é uma doença quieta, ela vem e vem quietinha. (E14).
Essa condição permitiu a continuidade do cuidado.

Ressalta-se que a forma de agir do profissional que realiza o exame foi citada como facilitadora desde o momento da coleta do preventivo, pois, apesar de sentir "vergonha mesmo, a enfermeira [Nome], ela me deixa bem à vontade" (E08). A relação de afeto e confiança entre usuária e profissional é ilustrada na fala de outra mulher entrevistada:

Tanto pelas enfermeiras quanto as enfermeiras chefes, eu fiz o exame aqui, aí ela chegou pra mim e conversou, explicou tudo certinho, e o tratamento também foi super tranquilo. No preventivo, me alertaram que eu estava com uma carne esponjosa na entrada do útero [...] foi muito legal. (E01).

As potencialidades e fragilidades no cuidado às mulheres que tiveram resultado do exame de $\mathrm{CO}$ alterado nos remete à proposta do acolhimento como diretriz operacional dos serviços de saúde. Ele acontece na relação usuário-serviço como um dispositivo para propiciar o acesso, o vínculo entre equipe-população, desencadear o cuidado integral e modificar a clínica, em um processo mediado pela capacidade dos trabalhadores de recepcionar, atender, escutar, dialogar, tomar decisão, amparar, orientar, negociar.

Para o Ministério da Saúde, o acolhimento é concebido como uma ação que acontece por meio de diálogos permanentes que alcancem a corresponsabilização do usuário no processo de produção da saúde (BRASIL, 2006). É um processo no qual trabalhadores e instituições tomam para si a responsabilidade a partir das principais necessidades de saúde (SOUZA ET AL., 2008).

Considerando a taxonomia adotada por Cecílio (2001), vale ressaltar que o vínculo, constitui uma necessidade de saúde a ser apropriada e trabalhada na prática cotidiana dos serviços de saúde. A criação de vínculo se consolida na relação de confiança que o usuário estabelece, a qual acontece ao longo 
do tempo, com caráter pessoal, intransferível, de forma solidária.

Entretanto, apesar do que foi relatado pelas outras entrevistadas, uma usuária declarou não haver escuta por parte do trabalhador de saúde. O contato para informar sobre o diagnóstico foi feito de maneira impessoal, e o encaminhamento para outro serviço realizado sem o esclarecimento sobre o agravo e/ou tratamento proposto: "Não sei quem me encaminhou, só sei que ligaram pra mim, e eu fui o ano passado" (E13). Esse depoimento nos leva a inferir que, nessa situação, $o$ atendimento não esteve centrado no usuário, o que faz com que o mesmo assuma a condição de objeto, sendo colocado à margem do plano terapêutico (SOUZA ET AL., 2010).

A falta de interação e vínculo pode ter gerado expectativas que não foram alcançadas, frustrações com relação ao cuidado prestado em uma das participantes do estudo. Esta disse ter ficado "chateada [...] eu fui lá duas vezes [...] só tomei um remédio, um comprimido, e só, só isso aî" (E03). Tal situação também foi referida como geradora de "medo": "Assim, é que eu nunca tinha feito. Ninguém me explicou essas coisas. Eu que tive que ir atrás pra saber" (E07). Mesmo tendo sido relatada a falta de interação com o profissional de saúde, em alguns casos, várias usuárias citam o vínculo com a família como fator que ajudou na continuidade do tratamento:

Assim, quando eu cheguei e contei pra minha família, todo mundo me apoiou. 'Você vai fazer o tratamento, você é forte, não é o bicho de sete cabeças. Você vai tratar e vai melhorar'. Então, eu fui bem tranquila também. (E11).

Para outra usuária entrevistada, o sentimento de fé em Deus se constituiu como estimulador de uma atitude de confiança e otimismo:

Falei com Deus e pensei que não era pra eu me preocupar, daí deu tudo certo. Eu fiz o exame e a enfermeira falou que era pra me preparar para o tratamento. Pensei: nada do que elas estão falando é verdade. Eu falei: Senhor, eu vim aqui, o Senhor está no comando [...] então, fiquei bem tranquila (EN12).

Segundo Jaspard (2004, P. 208), apesar de o sofrimento ser, "antes de tudo, uma realidade existencial comum e autônoma no plano simplesmente humano", para aqueles que têm fé e creem, com confiança, Deus está próximo dos que sofrem e os sustenta. Esse sentimento faz com que adotem uma postura que os estimula positivamente no enfrentamento das dificuldades experienciadas.

\section{Conclusões}

O acesso à coleta da citologia oncótica atendeu à demanda apresentada e ultrapassou a cobertura estabelecida pelo programa, o que é fundamental, já que se constitui como a porta de entrada das mulheres para o cuidado, no tocante à prevenção e ao tratamento do câncer de colo de útero.

No entanto, os resultados deixam evidentes as dificuldades quanto à realização da continuidade do cuidado, apresentando fragilidades referentes à localização de usuárias com resultado de exame alterado e oferta de serviços na unidade e em outros serviços da rede. Esse cenário compromete a efetividade do Programa e a integralidade do cuidado a essas mulheres, na medida em que fica evidente a falta de captação de algumas delas para o tratamento. Este estudo demonstrou que apenas o rastreamento isolado não garantiu a qualidade da atenção em saúde para o grupo estudado.

É necessário compreender a coleta do preventivo como a primeira parte do cuidado, que deve ser constantemente monitorada com o apoio de indicadores e metas. Entretanto, o serviço de saúde também deve voltar sua estrutura organizacional para garantir a continuidade do cuidado, 
imprescindível para gerar impacto sobre a situação de saúde de mulheres com o resultado de exame alterado.

Ainda que a postura acolhedora e o vínculo tenham sido percebidos como condicionantes para a qualidade da atenção e a efetividade do tratamento, esse caminho ainda não está consolidado, e parece impossível fazê-lo sem a participação de todos os envolvidos no processo saúde e doença, desde os usuários

\section{Referências}

BARDIN, L. Análise de conteúdo. Lisboa: Edições 70, 2009.

BRASIL. Ministério da Saúde. Secretaria de Gestão Estratégica e Participativa. Departamento de Articulação Interfederativa. Caderno de Diretrizes, Objetivos, Metas e Indicadores: 2013-2015. Brasília, DF: Ministério da Saúde, 2013.

Ministério da Saúde. Gabinete do Ministro. Portaria $\mathrm{n}^{\circ} 2.488$, de 21 de outubro de 2011. Aprova a Política Nacional de Atenção Básica, estabelecendo a revisão de diretrizes e normas para a organização da Atenção Básica, para a Estratégia Saúde da Família (ESF) e o Programa de Agentes Comunitários de Saúde (PACS): Diário Oficial [da] União, Brasília, DF, 21 out. 2011.

Ministério da Saúde. Secretaria de Atenção Básica. Núcleo Técnico da Política Nacional de Humanização. Acolhimento nas práticas de produção de saúde. 2. ed. Brasília, DF: Ministério da Saúde, 2006.

CAMPOS, G. W. S. A reforma da reforma: repensando a saúde. São Paulo: Hucitec, 1992.

Saúde Paidéia. São Paulo: Hucitec, 2003.

Subjetividade e administração de pessoal: considerações sobre modos de gerenciar trabalho em equipes de saúde. In: MERHY, E. E; ONOCKO, R. (Org). Agir em saúde: um desafio para o público. São Paulo: Hucitec, 1998. p. 229-266.

CARVALHO, G. Os governos trincam e truncam o conceito de integralidade. Radis: Comunicação em Saúde. Rio de Janeiro, n. 49, p. 16, set. 2006. aos trabalhadores e gestores.

Recomenda-se a constante realização da avaliação do programa de câncer para além de aspectos como a cobertura da realização do exame. Deve-se considerar o funcionamento da rede de atenção voltada para esse grupo, avaliando o acesso e a continuidade das usuárias ao tratamento.
CECÍLIO, L. C. O. As necessidades de saúde como conceito estruturante na luta pela integralidade e equidade na atenção em saúde. In: PINHEIRO, R.; MATTOS, R.A. (Org.). Os sentidos da integralidade da atenção e no cuidado à saúde. Rio de Janeiro: IMS/UERJ, ABRASCO, 2001. p. 113-127.

FIGUEIRÓ, A. C.; FRIAS, P. G.; NAVARRO, L. M. Avaliação em saúde: conceitos básicos para a prática nas instituições. In: SAMICO, I. et al. (Org.). Avaliação em saúde: bases conceituais e operacionais. Rio de Janeiro: MedBook, 2010. p. 1-14.

INSTITUTO BRASILEIRO DE GEOGRAFIA E ESTATISTICA (IBGE). Censo demográfico: Resultados da Amostra, Características da População. 2010. Disponível em: <http://www.ibge.gov.br/cidadesat/ xtras/temas.php?codmun=411370\&idtema $=90 \&$ search $=$ parana|londrina|censo-demografico-2010:-resultados-da-amostra-caracteristicas-da-populacao->. Acesso em: 20 fev. 2013.

INSTITUTO NACIONAL DO CÂNCER (INCA). Divisão de Apoio à Rede de Atenção Oncológica. Programa Nacional de Controle do Câncer do Colo do Útero. [Rio de Janeiro]: Inca, 2011. Disponível em: <http://wwwl.inca. gov.br/inca/Arquivos/PROGRAMA_UTERO_internet. PDF>. Acesso em: 14 abr. 2014.

JASPARD, J. Significação religiosa do sofrimento e posição psicológica na fé. Psicol. USP, São Paulo, v. 15, n. 3, p. 191-212, 2004.

LONDRINA. Prefeitura Municipal. Prevenção do câncer de colo uterino e mama. Londrina: Prefeitura Municipal, 2006. 
MAGALHÃES JÚNIOR, H. M. Prefácio. In: SILVA, S.

F. (Org.). Redes de atenção à saúde no SUS: o pacto pela saúde e redes regionalizadas de ações e serviços de saúde. Campinas: Idisa, 2008. p. 7-10.

MATTOS, R. A. Os sentidos da integralidade: uma reflexão acerca dos valores que merecem ser defendidos. In: PINHEIRO, R.; MATTOS, R. A. (Org.). Os sentidos da integralidade na atenção e no cuidado à saúde. Rio de Janeiro: ABRASCO, 2001. p. 39-64.

MERHY, E. E. A perda da dimensão cuidadora na produção de saúde: uma discussão do modelo assistencial e da intervenção no seu modo de trabalhar a assistência. In: CAMPOS, C. R. (Org.). Sistema Único de Saúde em Belo Horizonte: reescrevendo o público. São Paulo: Xamã, 1998, p. 103-120.

MERHY, E. E. A cartografia do trabalho vivo. São Paulo: Hucitec, 2002.

MERHY, E. E. et al. O trabalho em saúde: olhando e experienciando o SUS no cotidiano. São Paulo: Hucitec, 2003.

OLIVEIRA, A. et al. A comunicação no contexto do acolhimento em uma unidade de saúde da família de São Carlos, SP. Interface (Botucatu), Botucatu, v. 12, n. 27, p. 749-762, 2008.

SALA, A.; NEMES, M. I. B.; COHEN, D. D. A avaliação e a prática programática. In: SCHRAIBER, L. B.; NEMES, M. I. B.; MENDES-GONÇALVES, R. B. (Org.). Saúde do Adulto: programas e ações na unidade básica. São Paulo: Hucitec, 1996. p. 173-192.

SANTOS, A. L.; RIGOTTO, R. M. Território e territorialização: incorporando as relações produção, trabalho, ambiente e saúde na atenção básica de saúde. Trab. Educ. Saúde, Rio de Janeiro. v. 8, n. 3, p. 387-406, 2010.

SANTOS, A. L. A comunidade do mangue do bairro Vila Velha, Fortaleza/CE: o território e o cotidiano vivido a partir da perspectiva dos moradores e dos profissionais do Programa de Saúde da Família (PSF). 2008. 248 f. Dissertação (Mestrado em Saúde Pública) Faculdadede Medicina, Universidade Federal do Ceará, Fortaleza, 2008.
SILVA JUNIOR, A. G.; MASCARENHAS, M. T. M.

Avaliação da Atenção Básica em saúde sob ótica da integralidade: aspectos conceituais e metodológicos. In: PINHEIROS, R.; MATTOS, R. A. (Org). Cuidado: as fronteiras da integralidade. São Paulo: Hucitec; Rio de Janeiro: UERJ, 2004. p. 241-257.

STARFIELD, B. Atenção primária: equilíbrio entre necessidades de saúde, serviços e tecnologia. Brasília, DF: UNESCO: Ministério da Saúde, 2004.

SOUZA, E. C. F. et al. Acesso e acolhimento na atenção básica: uma análise da percepção dos usuários e profissionais de saúde. Cad. Saúde Pública, Rio de Janeiro, v. 24, sup. 1, p. S100-S110, 2008.

SOUZA, K. M. J. et al. Abandono do tratamento de tuberculose e relações de vínculo com a equipe de saúde da família. Rev. esc. enferm. USP, São Paulo, v. 44, n. 4, p. 904-910, dez. 2010.

\section{WORLD HEALTH ORGANIZATION (WHO).}

International Agency for Research on Cancer. Globocan 2012. Lyon, 2012. Disponível em: <http://globocan.iarc. fr/>. Acesso em: 14 abr. 2014.

Recebido para publicação em abril de 2014

Versão final em dezembro de 2014

Conflito de interesses: inexistente

Suporte financeiro: não houve 